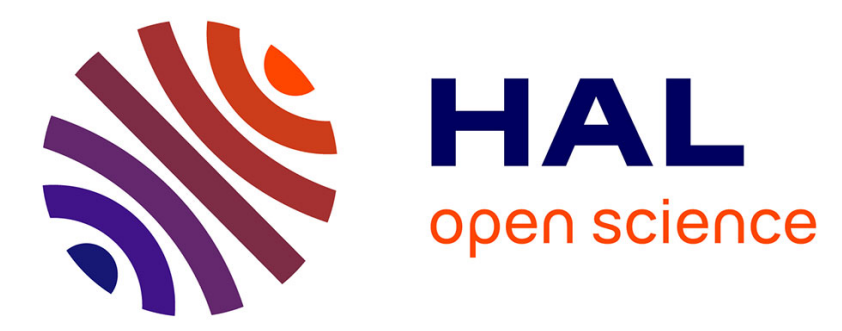

\title{
When vagueness is a strategic resource for planning actors
}

\author{
Thomas Buhler
}

\section{To cite this version:}

Thomas Buhler. When vagueness is a strategic resource for planning actors. Planning Theory, 2021, pp.147309522199586. 10.1177/1473095221995861 . hal-03152254

\section{HAL Id: hal-03152254 \\ https://hal.science/hal-03152254}

Submitted on 15 Apr 2021

HAL is a multi-disciplinary open access archive for the deposit and dissemination of scientific research documents, whether they are published or not. The documents may come from teaching and research institutions in France or abroad, or from public or private research centers.
L'archive ouverte pluridisciplinaire HAL, est destinée au dépôt et à la diffusion de documents scientifiques de niveau recherche, publiés ou non, émanant des établissements d'enseignement et de recherche français ou étrangers, des laboratoires publics ou privés. 
WHEN VAGUENESS IS A STRATEGIC RESOURCE FOR PLANNING ACTORS

Thomas Buhler*

*ThéMA, UMR 6049 CNRS / Université Bourgogne Franche-Comté thomas.buhler@univ-fcomte.fr

This is a postprint version, the definitive version of this paper is :

Buhler, T. (2021). When vagueness is a strategic resource for planning actors. Planning Theory. https://doi.org/10.1177/1473095221995861

\section{Abstract}

This paper focuses on the use of vague discourse in planning. Early contributions identified vagueness as a 'problem' to be solved so as to avoid potential misunderstandings and conflicts. This paper adopts the complementary point of view whereby vagueness can also be a 'resource' i.e. a strategy used by actors in adverse circumstances. A systematic analysis of the texts and illustrations of 36 urban transport plans shows that vagueness is an essential ingredient. It is used mainly as a way to hedge against unwanted public commitments in the context of major uncertainties and tension between actors.

Keywords:

Vagueness, vague discourse, planning discourse, visual content analysis, textometry, local transport planning 


\section{INTRODUCTION}

Over the last twenty years, a long series of research papers has viewed plans as 'signals' sent by actors to others interacting in the same area (i.e. municipalities, developers, government agencies, regional agencies, grassroots organisations, etc.) (Hoch, 2007; Hopkins, 2001; Hopkins and Knaap, 2018 ; Kaza and Hopkins, 2009). This research does not break with previous theoretical models in urban planning but supplements them by considering the plans themselves - and not the governance process preceding them - as a research object in their own right. In planning theory, this research is distinguished by its phenomenological approach as it analyses plans as they are (and how they work) and not as they should be. It thus takes into account the multi-institutional setting and the constraints that influence the making of plans, i.e. the interdependence between actors, the indivisibility and irreversibility of actions undertaken, and the imperfect foresight which always leaves some degree of uncertainty (Hopkins, 2001). Many new perspectives have been opened up. For example, the circumstances in which it is necessary (or unnecessary) to make public a plan and/or the deliberative process that brought it about have been explored (Kaza and Hopkins, 2009). Similarly the reasons that impel actors to participate or not in a coalition around a plan have been analysed (Hopkins and Knaap, 2018).

Although this approach has made many contributions, it seems that empirically it relies heavily on examples drawn mainly from urban contexts in the United States. Most of these cases concern either (1) comprehensive plans or more generically urban development plans, and other organisations' plans that conflict, contradict or complement them (Hopkins, 2001; Hopkins and Knaap, 2018; Kaza and Hopkins, 2012) or (2) cases that stand apart from the ordinary planning context, such as reconstruction after hurricane Katrina (Kaza and Hopkins, 2009). This empirical emphasis has led these analyses to focus on concerns that are particularly relevant for US planners and the other actors interacting with them in these contexts (for example: Should I make my plan pubic? With what agents should I make plans? etc.). 
However, it seems that making comprehensive plans and urban development plans in the United States involves a number of specificities, including their voluntary character in most states where comprehensive planning processes are mostly called for by local actors. For the 'plans as signal' model ${ }^{1}$ to become more universal, it seems necessary to challenge it in other multi-institutional settings, especially settings where central government or other higher level actors require local authorities to produce plans.

Our central hypothesis in this paper is that when planning is conducted in adverse circumstances from the point of view of the local authority, discursive vagueness is used in texts and visuals to hedge against commitments being given that are too specific. By 'adverse circumstances' we mean any of the many situations where it is not the local authority itself that takes the initiative in producing a plan. This can occur, for example, when the plan is mandatory and its topics or sections are imposed by higher-level actors; when local authorities have little initial intention of planning on certain subjects; or when external funding for infrastructure or projects is made conditional upon the existence of such a plan. The rationales behind the use of vagueness might imply the need to dissimulate one's true plan and/or to put up a smokescreen by way of wording that does not imply firm or actionable commitments. It is in this sense that we could consider vagueness as a 'resource' since it is 'an action or a strategy which may be adopted in adverse circumstances' (Lexico Oxford Dictionary, 2020).

The present paper is based, then, on the analysis of French local transport plans (Plans de Déplacements Urbains or PDUs) which are mandatory plans and have long been perceived by local authorities as an additional requirement imposed on local authorities 'by Paris' (Offner, 2006). In order to identify the importance and the role of vagueness in planning discourse, we conduct an exhaustive analysis of both textual and iconographic elements of 36 plans (two editions for each of 18 French cities over the period 2000-2015).

\section{VAGUENESS IN PLANNING}

\footnotetext{
${ }^{1}$ Several names can be found in the literature of this line of research: the 'Illinois School' approach, the 'interacting plans perspective', 'autonomous planning'. Although they are not absolutely congruent, we analyse them here as belonging to the same block considering 'plans as signals'.
} 


\subsection{What is vagueness?}

The notion of vagueness is much discussed currently in the fields of philosophy, logic and semantics (Keefe, 2000; Shapiro, 2008; Sorensen, 2018). A hundred years ago now, Bertrand Russell (1923) proposed a seminal contribution in which he emphasised a number of points that are central to our present reflexion.

First of all, vagueness is an inherent characteristic of any system of representation of the world, be it language, photography or painting. Vagueness does not characterise the things of the world but the system that aims to represent it. In the case of language, vagueness occurs whenever there are borderline cases, i.e. when there are statements that cannot be said to be either true or false. For example, it is impossible to precisely define the limits of what we call the colour 'red' on the continuum of all colours. For some shades, it will be difficult to say whether they are 'red' or not. The same applies to the limits of what is a 'tall', 'fat' or 'bald' man. Russell concludes that in natural languages, every word has a part of a vagueness in it.

To clarify the point, it is necessary to establish the difference between what is vagueness and what is ambiguity. Many words are both vague and ambiguous, making it difficult to distinguish between them (Sorensen, 2018). That said, these two categories of terms add to the blur of a statement in different ways. Ambiguity blurs meaning when a word has several senses that coexist. On the contrary, vagueness depends on context, which can sometimes be clarified (for example, someone can be 'tall for an eighteenth century French man') (Sorensen, 2018).

In contrast with both ambiguity and vagueness, a totally 'precise' language would propose a single word for everything in the world, and conversely every word would designate only one thing, with clear limits. Russell (1923) calls this a 'one-to-one' system. However, such correspondence never occurs in natural languages, which are 'one-to-many' systems.

A second point interests us in this contribution by Russell (1923). Although every word and every statement contains some amount of vagueness, it can be in very different proportions. Russell uses 
the comparison with the scale of maps to show that the vagueness of a formulation can be more or less pronounced.

A small-scale map is usually vaguer than a large-scale map, because it does not show all the turns and twists of the roads, rivers, etc., so that various slightly different courses are compatible with the representation that it gives. Vagueness, clearly, is a matter of degree. (Russell, 1923: 90)

This idea of degree is at the core of our present thinking as we are looking to identify the latitude that the actors involved in public planning have for formulating their assessments, strategies, objectives and associated actions more or less vaguely.

One last point raised in Russell (1923) is of interest to us here. Contrary to what is commonly assumed, he insists that vague propositions are not false by nature. On the contrary, they maximise their chances of being 'true', since many different configurations of forthcoming events can validate them. By contrast, a fully specific proposition could only be considered 'true' in one and only one configuration, i.e. the one described in the initial proposition. In other words, by announcing vague things we maximise the chances of not being mistaken.

At the end of these introductory theoretical points, it is clear that any plan, like any document involving textual and visual elements, contains a part of vagueness because the words and images that constitute it are vague by nature. That being said, for a given subject there is a whole range of possible discourses from 'extremely vague' to 'highly specific'. As an example, the four formulations below all contain a certain amount of vagueness (in particular with respect to 'who?', 'where?' and 'when?'). That said, formulation no. 4 contains a more specific and explicit commitment since it stipulates the type and lengths of infrastructure to be put in. 
Our objective is ...

[1] 'to develop a high quality network for cycling mobility'

[2] 'to extend and to create new links within the current cycling network'

[3] 'to create $15 \mathrm{~km}$ of cycle paths and lanes'

[4] 'to create an extension of the current cycling network of $10 \mathrm{~km}$ of new dedicated cycle paths and $5 \mathrm{~km}$ of cycle lanes'

This simple example shows us that there is a possible gradient of vagueness within planning discourse with clear implications in terms of commitment and risk-taking, particularly when a future ex-post evaluation phase is scheduled. Indeed, if the objectives are not achieved, 5 or 10 years after the plan's approval and publication, it would be easier to defend and justify proposition no. 1 than proposition no. 4.

\subsection{Vagueness in other fields of research}

Currently there seems to be a revival of interest in the concept of vagueness in the social sciences and humanities. Although it is not massively addressed in planning theory, other disciplines can provide insights into the question.

For instance, some recent research in political science views discursive vagueness as a force for coalition-building, in addition to the classical drivers that are well identified by the Advocacy Coalition Framework (i.e. resources, interests and normative beliefs) (Sabatier, 2010). In European Union defence and energy policies, certain vague wording and discourses help to build temporary coalitions of countries and prevent strong opposition from forming (Jegen and Mérand, 2014). That said, the authors insist that this 'constructive ambiguity' has its limits and can only work for a time. A more explicit form of content must ensue whereby coalitions' views can be materialised in proposed legal texts (Jegen and Mérand, 2014). Although the geopolitics of urban planning are usually simpler than European diplomacy, it is hard to believe that this strategic use of discursive vagueness is only to be found within European institutions.

Apart from political science, linguistics too is a research area with an analytical and critical perspective on discourse in general and discursive vagueness in particular. More specifically, the 'critical discourse analysis' (CDA) perspective develops an analytical view of how language is actually 
used in different social contexts, and not how it 'should' be used (Fairclough, 2013). CDA insists that the ideological aspects of discourse emanating from dominant actors are not transparent. Consequently, CDA seeks to reveal these ideological aspects of discourse by deconstructing texts and examining their social contexts of production and their respective social practices thereby revealing the social forces behind the discourse. For CDA, vagueness is not a problem with statements but a resource for dominant actors (Krieg-Planque, 2012).

For discourse theory, each text - whether a transcript of conversations or a published document - can be pinned to a particular social context and a type of discourse. For this field of linguistics, the discourse found in plans relates to institutional discourse (as opposed to other types of discourse such as media discourse or political discourse) (Buhler and Lethier, 2019; Krieg-Planque, 2012; Krieg-Planque and Oger, 2010). Four main points describe this type of discourse which is fully congruent with the content and style of planning documents.

\begin{tabular}{|c|c|c|}
\hline & $\begin{array}{l}\text { Four distinctive dimensions } \\
\text { of institutional discourse } \\
\text { (in general) (Krieg-Planque, } \\
\text { 2012) }\end{array}$ & $\begin{array}{l}\text { 'Planning discourse' found in planning documents } \\
\text { (in particular) (Buhler and Lethier, 2019) }\end{array}$ \\
\hline & $\begin{array}{l}\text { A type of discourse } \\
\text { I with a marked active and } \\
\text { performative dimension. }\end{array}$ & $\begin{array}{l}\text { Planning documents, by definition, aim at } \\
\text { modifying city structures and regulating private } \\
\text { initiatives. }\end{array}$ \\
\hline I & $\begin{array}{l}\text { A discourse } \\
\text { produced by an institution, } \\
\text { emanating from a } \\
\text { collective entity presented } \\
\text { as indivisible ... }\end{array}$ & $\begin{array}{l}\text { In most cases, local planning documents are } \\
\text { drawn up by a variety of actors under the supervision } \\
\text { and legal responsibility of a local public entity. }\end{array}$ \\
\hline II & $\begin{array}{l}\text { I... while being the } \\
\text { among various points of } \\
\text { view. }\end{array}$ & $\begin{array}{l}\text { Actors participating and negotiating in the } \\
\text { process are mentioned but the final outcome is } \\
\text { presented as a collective product without dissenting } \\
\text { points of view. }\end{array}$ \\
\hline V & $\begin{array}{l}\text { A type of discourse } \\
\text { guided by a dual principle } \\
\text { of } \begin{array}{ll}\text { (a) stabilisation of } \\
\text { statements and } \quad \text { (b) }\end{array} \\
\text { elimination of conflict. }\end{array}$ & $\begin{array}{l}\text { (a) Stabilised statements are very frequent in the } \\
\text { corpus of planning documents analysed in this } \\
\text { paper. } \\
\text { (b) Conflicts among actors are almost never expressed } \\
\text { in planning documents. }\end{array}$ \\
\hline
\end{tabular}

Table 1: Planning documents as a denial of conflict 
The most important feature for this paper is the tendency in planning discourse to remove all signs of pre-existing, current or even possible future $\operatorname{conflicts}^{2}$ (see Table 2 , section IV b). This particular feature converges with our guiding assumption that substantial vagueness is to be found in plans as this type of formulation is by nature more consensual.

\subsection{The limited occurrence of vagueness in planning thought}

Although philosophers, like policy and discourse analysts, have done a lot of work on the issue of vagueness, there are currently few contributions on the subject in planning theory. The multiauthored book Fuzzy Planning (De Roo and Porter, 2007) offered an initial input to the study of vagueness $^{3}$ in planning. That said, the book is more a methodological proposal for planners than a study of the importance and role of vagueness in plans. Indeed, it considers vagueness as a 'problem' for planning and planners. This 'problem' is described as being four-fold in character, with one aspect being of prime interest in this paper: 'conceptual fuzziness' or in other words the polysemy associated with most planning concepts, such as the 'compact city' or the 'transition city'. ${ }^{4}$ The authors assert that this polysemy generates misunderstandings and potential conflicts among actors (Porter and De Roo, 2007). It is clear that the concepts used in urban planning are frequently and particularly fluid, elusive and fuzzy. However, it is worth re-examining the rationale behind their idea of 'conceptual fuzziness'. From a critical perspective, two points seem to have been overlooked in this framework.

First, it is indeed assumed - and explicitly stated many times in the book - that planners often disregard the polysemy of planning concepts and the subsequent risks of misunderstanding or conflict.

A substantial part of this fuzziness may be the result of ignoring the fact that there is not one but many different understandings and perceptions of concepts such as 'sustainability'. (Porter and De Roo, 2007: 2)

\footnotetext{
2 A few rare counter-examples can be found, of course. For example, disagreements have been formally expressed between regional transport documents and local land use in some rare documented cases (Hopkins, 2007).

${ }^{3}$ For ease of reading we will consider "fuzziness" and "vagueness" here as perfect synonyms.

${ }^{4}$ In addition to this 'conceptual fuzziness', three other dimensions are identified: (1) 'fuzzy governance' when responsibilities between actors are not clearly assigned and when the open or closed nature of decision-making is not clearly specified by law; (2) fuzziness associated with regional and intermediate actors' strategies; and (3) the use of specific indicators directed at the planning process at the expense of elements about its content. These reflections and developments are not questioned here in their entirety.
} 
For Porter and De Roo (2007) planning with deliberate disregard for ambiguity of terms used, is a problem that should be solved to avoid potential conflicts. This interpretation implies that it would suffice to formulate more precisely assessments, objectives, strategy and actions to avoid conflicts. This interpretation overlooks the deep-rooted reasons why an actor or group of actors actually use vagueness in planning.

Second, and more importantly, in this research discursive vagueness is associated exclusively with the concepts handled by planners. From a discourse analysis perspective, this seems odd as vagueness concerns not only the concepts put forward but 'planning discourse' as a whole. In other words, all the ways in which urban planning actors express, formalize, illustrate and write their assessments, strategies, objectives and actions to be put in place in the future can be theoretically subject to vagueness (Krieg-Planque, 2012; Russell, 1923).

Other research in planning theory has identified vague aspects in plans. Referring to a plan made by the city of New Orleans in the post-Katrina context, Kaza \& Hopkins (2009) identify a case where the signal sent is particularly vague.

A commitment to a goal of "equality of housing opportunity" is not a commitment to a particular subsidy or a specific regulation. (...) When a plan for a city publicly declares such a commitment as an objective, it leaves vague the question of which particular action will achieve this intention. The commitment to goals allows flexibility in choosing particular actions or sets of actions as the situation demands. However, committing only to goals postpones the decisions and commitment to actions, which may be advantageous or not, or advantageous to some and not others. (Kaza and Hopkins, 2009: 495-496)

In this example, the urgency of the situation clashes with the difficulties of convergence of actors in a multi-institutional setting. Vagueness appears here to be a sufficiently satisfactory solution for the city to send a multiple signal through this plan. A first signal about the objectives displayed to reassure the population, as well as a second signal aimed more at other organisations, which states that little concrete and precise will be done in a short period of time. Through this example, Kaza \& Hopkins (2009) show that vagueness can be used (1) when there is a pragmatic need to hedge against overly firm commitments in a context of very high uncertainty, and (2) when other actors have the keys to disambiguate what is being said. 
Hoch (2007) completes this line of research by setting the idea of a maximum acceptable degree of vagueness in plans. Indeed, beyond a certain degree, plans can no longer be considered credible.

Plans that say little about how to turn policy into projects may be said to lack means-ends coherence. (Hoch, 2007: 21)

It seems, therefore, that there is a certain latitude within public plans for using discursive vagueness. This latitude seems to be bounded (1) by the minimal vagueness inherent in any word or visual representation, and (2) by the maximum acceptable degree of vagueness that could compromise the existence of the plan. This paper proposes to explore this discursive latitude, by not limiting itself to vague concepts or catchphrases, but by measuring and tracking a wide variety of elements in a large series of plans.

A systematic analysis of textual and visual elements was thus conducted on a corpus of French local transport planning documents for the period 2000-2015. Before going into the details of the method, it is fundamental to have a clear understanding of the governance context surrounding these plans.

\section{PDUS AND THEIR GOVERNANCE CONTEXT}

French local transport plans, termed Plans de déplacements urbains (PDUs), will be considered in this paper for an investigation of vagueness. In a nutshell, PDUs are mandatory plans in France for the 66 cities of more than 100,000 inhabitants. In terms of content, PDUs are typical urban transport plans as they concern planning means of transport for people and goods on the scale of the conurbation. They have to be revised every ten years.

The overall objective is clear and explicit: the local authorities must, through a PDU, explain their strategy to limit and reduce car-use in the city. Many topics of these plans are also imposed by the legal framework, namely the infrastructures and services to be put in place, tools to reduce car-use (speed limits, parking and access restrictions, toll charges, etc.), information and communication devices to encourage changes in travel modes, urban logistics and accessibility issues for people with reduced mobility. The main thrust of the discourse lies in the new infrastructures and services to be 
put in place. They are, however, voluminous documents (with an average of 62,000 words or approximately 200 pages) that deal with all other imposed subjects generally in fewer pages.

To fully understand the current context of governance around PDUs, it is important to go back to the beginnings of local transport planning in France, almost forty years ago. Indeed the drafting of local transport plans in France has a rather turbulent history that can be summarised around four key moments. PDUs were introduced by (1) the LOTI act in 1982. At that time, the guiding idea was to enable local transport authorities to plan all modes of transport on the scale of the conurbation. This act emerged in a broader context of government decentralisation following the election of François Mitterrand as President of the Republic in 1981. As many functions of the central government were at the same time assigned to local authorities, generating significant institutional transformations, it was decided to make these plans optional so as not to overburden the local authorities. As a result, only a few authorities actually showed any interest in PDUs and fully implemented a plan. Political changes in France in the 1980s then resulted in the act becoming inapplicable, obsolete and then forgotten.

An important clarification needs to be made here. The 'decentralisation' of planning responsibilities to the municipalities and other local authorities which has been going on in France since that time does not involve a total delegation of power. In French urban planning law, one principle remains fundamental. Although the municipalities and local authorities are in charge, they are only the local administrator in the name of the State, which remains the legal guarantor of national interests and the legality of the various local plans. In concrete terms, this means that any urban development plan, if it is to be approved and become effective, will have to pass the scrutiny of the Prefects, i.e. the representatives of the central government in the French 'régions' and 'départments', and their administrative staff.

Fourteen years after the LOTI act, PDUs surprisingly reappeared in 1996 through the LAURE act (2) that does not directly concern transport, but air quality. The LAURE act made PDUs compulsory for cities of more than 100,000 inhabitants with the obligation to develop a strategy to reduce car-use in the city. Although mandatory, French cities were very slow to embrace the plans, which were seen by 
many as an additional requirement by central government (Offner, 2006). As a result, only a few cities had a plan approved within the three-year deadline (i.e. in 1999).

In order to ensure compliance, the central government introduced the SRU act (3) of 2000 requiring a city to have an approved PDU to apply for central government subsidies for any 'dedicated public transport lane' (i.e. tram or BRT projects). This obligation was obviously not insignificant as at that time the great majority of French cities were planning to implement or extend new tramways. Once this financial constraint came into operation, many first-generation PDUs were drafted and adopted between 2000 and 2004.

The 2000 SRU act not only stipulated the necessity of having an approved PDU for claiming central government subsidies, it also reorganised the French national planning system. Since 2000, PDUs have played a more central role than before. For instance, local urban planning schemes (PLUs 'plans locaux d'urbanisme'), defining land-use at the municipality level, have to be consistent with their respective PDUs. ${ }^{5}$ And the PDU in turn has to be compatible with broader supra-local guidelines. Although PDUs have become more central, they cannot be considered to be a major commitment because no legal consequences ensue if the objectives are not attained or if the actions announced are not implemented.

Ten years later, at the beginning of the 2010s, the second-generation of revised PDUs had to fulfil a new requirement which is of interest in this paper. These documents had to integrate an environmental evaluation (4) of the impact of the previous version of the plan. Environmental evaluations appeared in the French planning framework in 2004 with the transposition of European Directive 2001/42/EC into national law.

The overall context of governance around these plans exhibits rather peculiar signs. After dragging their feet for many years, and even in some instances displaying their disinterest, local authorities began to draw up local transport plans under financial constraint. For their first edition in

\footnotetext{
${ }^{5}$ More specifically PLUs (land-use plans) have to be consistent with PDUs on the question of the number of possible private parking spaces per type of plot, as well as on the specification of plots necessary for future transport infrastructure projects.
} 
the early 2000s, the aim of securing central government funding seemed central for cities. In their revised version, in the early 2010s, local authorities wrote their PDUs in the knowledge that they would be evaluated ten years later. They spelled out more general and diverse objectives that were less oriented towards infrastructure issues because their first tramway lines were already operational (Buhler and Lethier, 2019).

In order to identify and describe the importance and the forms of vagueness in PDUs, we analysed both their textual and visual elements. This calls for methodological developments suitable for each type of content.

\section{AN EXHAUSTIVE READING OF TEXTUAL AND ILLUSTRATIVE VISUAL ELEMENTS}

\subsection{Plans as an exclusive source of investigation}

In this paper, the analysis of planning discourse is focused exclusively on plans for theoretical and methodological reasons. Theoretically, plans themselves can be considered an important object of research (Hopkins and Knaap, 2019). They are not only the outcome of a certain political or governance process. A major strand of research has demonstrated their worth when it comes to studying their communicational and informational dimensions (i.e. the signals they convey) (Hopkins, 2001; Hopkins and Knaap, 2018, 2019; Kaza, 2019; Kaza and Hopkins, 2009, 2012).

Methodologically, analysing planning discourse can rely on a wide spectrum of sources (preparatory documents, consultation meeting transcripts, press releases and so on) and techniques (interviews, archival work or observation of planning meetings) (Bugg and Gurran, 2011; Maccallum and Hopkins, 2011; Matthews and Satsangi, 2007; Portugali and Alfasi, 2008). Although there are many possible sources and methods, discourse analysis involves creating and analysing corpora of documents which must be comparable in terms of their purpose, type, size and style. Comparing documents as diverse as e-mails, meeting minutes and planning documents mixed in different corpora would make no sense in our research. Consequently the analysis deployed here relies on a corpus of plans that are similar in purpose, form, discourse type and size. Even if these are 'only' one step in a 
longer series of communication interactions, these documents are still the only legal and published written records in the overall process. They are drafted, checked, modified and re-checked by multiple actors before being approved and circulated. In this respect they can be considered as encapsulating both explicit and hidden strategies, negotiated by actors with different levels of power. In more pragmatic terms, these documents are also rather easily accessible as at least their latest version can be found online mainly as PDF documents (Hansson, 2020).

To test our hypothesis on the importance and role played by vagueness in plans, we had to go beyond the case of a single city located in a particular multi-institutional setting with its own history and local specificities (topography, presence of a coastline, a close border, etc.) which can have a strong impact in terms of discourse and the terminology used. The present textometric analysis is based on 18 cities which are representative of the diversity of the French cities mandated to implement PDUs (in terms of size, political colour of the executive, etc.). In order to be able to follow discursive vagueness over time, we have selected two editions of PDUs for each city: the first and the revised version.

\subsection{Methodological developments for textual elements}

As these 36 documents contain 1.6 million graphic forms, and as the respective importance of certain words and statements in the document are of interest here, a textual data analysis (TDA) method was chosen. The chosen method is Textometry, which is a computer assisted method that allows both synthetic and quantified analysis together with qualitative reading of the 'real' excerpts concerned by the analysis. This 'double scale' reading allows us to build informed interpretations and minimize possible misinterpretations due to the polysemy of certain words. ${ }^{6}$

It seems appropriate here to use an explicit, systematic and replicable method such as Textometry for two main reasons. First, the exclusively qualitative discourse analyses that are in the

\footnotetext{
${ }^{6}$ An exhaustive methodological paper has recently been published on the use of textometry in planning documents (Buhler and Lethier, 2019). It may be useful to refer to it for further details as, in the space constraints of this paper, we have to restrict ourselves to summary explanations just sufficient to understand the relevance of such a systematic method in the case of vague discourse.
} 
majority in the field have the regrettable tendency of being overly general at times about an expression or catchphrase without really identifying its importance in the document (Jacobs, 2006). The replicability of such works is thus very limited as the interpretative path followed is not always made explicit. Using a systematic method enables us to avoid such pitfalls and enables us to measure the number of real occurrences of a word or an expression in several plans.

Secondly, we seek to analyse the degree of vagueness in the plans. As stated above, 'vagueness, clearly, is a matter of degree' (Russell, 1923: 90). In other words, discursive vagueness is not binary. Some terms and phrases are fundamentally vaguer than others. A systematic method like Textometry makes it possible to recognise, measure and monitor these vaguer forms in time and to set them against the rest of the plan's discourse. Textomertry is also viewed as a contrastive method i.e. it makes it possible to compare the frequency of occurrence of certain terms or expressions among several documents or several generations of documents.

A supplementary remark is called for concerning texts: the form of textual vagueness is specific to each language. Linguistics has long identified that each language draws its own points of ambiguity and vagueness which are among the most difficult sentences to translate from one language to another (Saussure, 2005). Consequently, the categories used in our methodological development for texts in French are not directly transferable or translatable into another language.

For PDUs, we consider two kinds of textual vagueness (see Table 2). The first is generic. The categories of vague elements of this first type derive from discourse markers identified in the literature on institutional discourse in French (A to E, see Table 1) (Krieg-Planque, 2012; Pineira-Tresmontant, 1988; Thom, 1987). The second kind of textual fuzziness is specific to the discourse found in local transport planning and to its particular terminology and issues. The three categories identified derive from an analysis of the most frequent terms in local transport planning in France (Buhler and Lethier, 2019). Two of these categories ( $G$ and $H$, see Table 2 ) are defined by the negative comparison ('the elimination of ...') and thus need to be monitored over time to calculate how they change. 
Table 2 provides a summary of the various fuzzy elements considered for systematic textual analysis. These elements are not an exhaustive list of all substantially vague wording and terms, but they include their most frequent features. These elements have been sought in each PDU document, using the various query tools in the free and open source tool 'TXM'. 


\begin{tabular}{|c|c|c|c|c|}
\hline & Type & $\begin{array}{l}\text { Fuzzy } \\
\text { textual } \\
\text { element }\end{array}$ & $\begin{array}{l}\text { Rationale of use (+indicative number of } \\
\text { occurrences per category in the corpus) }\end{array}$ & Examples \& translation \\
\hline & \multirow{5}{*}{ 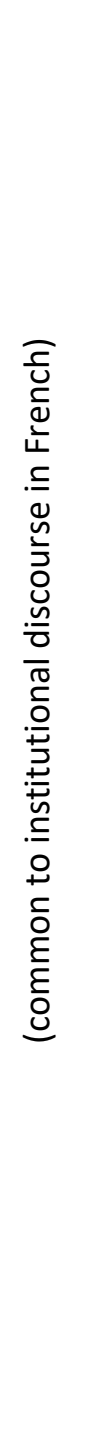 } & $\begin{array}{l}\text { [A] } \\
\text { Concessionary } \\
\text { wording }\end{array}$ & $\begin{array}{l}\text { The use of concessionary wording makes it } \\
\text { possible to say something and its opposite in the } \\
\text { same sentence. It blurs discourse while expressing } \\
\text { an apparently balanced position. }\end{array}$ & $\begin{array}{l}\text { "Ces mesures vont permettre d'inverser la tendance qui a facilité le tout } \\
\text { automobile grâce à un stationnement aisé, tout en composant avec la voiture } \\
\text { individuelle qui organise notre mode de vie et notre manière d'habiter en pays } \\
\text { d'Aix. " } \\
\text { (Aix-en-Provence, 2015, p. 77, 2nd paragraph of the 'strategy' section) } \\
\text { Translation: 'These measures will make it possible to reverse the trend that } \\
\text { has made car-use of prime importance thanks to easy parking, while at the same } \\
\text { time coming to terms with the individual car that organizes our way of life and our } \\
\text { way of living in the Pays d'Aix.' }\end{array}$ \\
\hline & & $\begin{array}{l}\text { [B] Verb } \\
\text { nominalizations } \\
\text { (when } \\
\text { verbs are } \\
\text { replaced by their } \\
\text { noun forms) }\end{array}$ & $\begin{array}{l}\text { This removes traces of mode, tense and } \\
\text { subject in relation to a verbal form. Responsibilities, } \\
\text { schedule and degree of certainty are thus } \\
\text { eliminated. }\end{array}$ & $\begin{array}{l}\text { "La desserte de la zone la plus dense sera recherchée par la mise en place } \\
\text { éventuelle d'une deuxième ligne de tramway pour assurer la desserte de la gare et } \\
\text { des pôles urbains du nord de la ville de Brest. » (Brest, 2014, p. 34) } \\
\text { Tr: 'The densest area will be served by the possible implementation of a } \\
\text { second tram line to serve the station and the urban centres in the north of the city } \\
\text { of Brest.' }\end{array}$ \\
\hline & & $\begin{array}{l}\text { [C] } \\
\text { 'Comparative } \\
\text { adjectives } \\
\text { without } \\
\text { comparison' }\end{array}$ & $\begin{array}{l}\text { This accentuates the importance accorded to } \\
\text { the noun and the idea without being specific about } \\
\text { the content as it is based on an innuendo. }\end{array}$ & $\begin{array}{l}\text { " Inciter aux mobilités douces et actives constitue l'une des principales } \\
\text { réponses au défi d'une agglomération moins dépendante de la voiture. " (Tours, } \\
2013, \text { p. 30) } \\
\text { Tr: 'Encouraging environmentally-friendly and active mobility is one of the } \\
\text { main responses to the challenge of a less car-dependent conurbation.' }\end{array}$ \\
\hline & & $\begin{array}{c}\text { [D] } \\
\text { 'Pointless } \\
\text { conjunctions' }\end{array}$ & $\begin{array}{l}\text { It fills the available space and gives the } \\
\text { impression of structuring the discourse without } \\
\text { actually adding meaning or precision. }\end{array}$ & 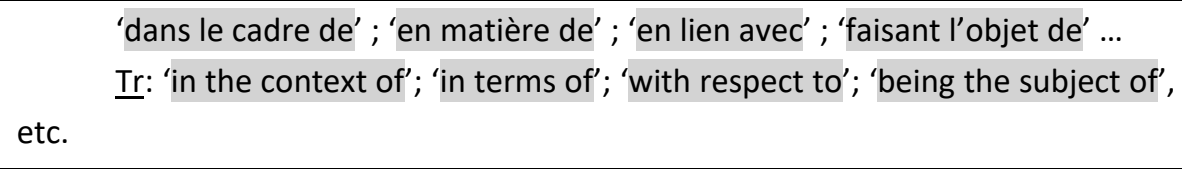 \\
\hline & & $\begin{array}{l}\text { [E] } \\
\text { 'Positivity effects' }\end{array}$ & $\begin{array}{l}\text { Reducing the impression of possible negative } \\
\text { effects through rhetorical wording, without adding } \\
\text { specific elements. }\end{array}$ & $\begin{array}{l}\text { «... organiser l'agglomération pour que piétons, cyclistes, deux roues } \\
\text { motorisés, bus, automobilistes et poids lourds circulent de manière rationnelle } \\
\text { sans compromettre la mobilité générale. " (Strasbourg, 2012, p. 28) }\end{array}$ \\
\hline
\end{tabular}




\begin{tabular}{|c|c|c|c|}
\hline & & & $\begin{array}{l}\text { Tr: ' } . . . \text { organizing the urban area so that pedestrians, cyclists, motorized two- } \\
\text { wheelers, buses, motorists and lorries can circulate in a rational manner without } \\
\text { compromising general mobility'. }\end{array}$ \\
\hline \multirow{3}{*}{ 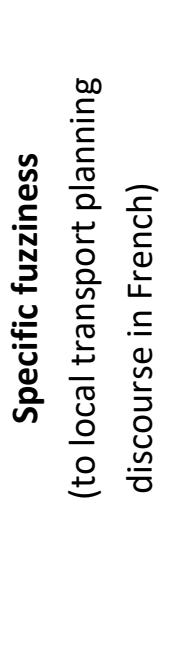 } & $\begin{array}{l}\text { [F] Fuzzy } \\
\text { concepts (+their } \\
\text { resp. adjectives } \\
\text { and verbs) }\end{array}$ & $\begin{array}{l}\text { Fuzzy concepts can be used to make } \\
\text { authoritative statements to be refined later once } \\
\text { the plan has been approved and financial resources } \\
\text { and precise timelines defined. }\end{array}$ & $\begin{array}{l}\text { 'cohérence' ; 'mobilité' ; 'territoire' ; 'durable' ; 'modes actifs' ... } \\
\text { Ir: 'coherence'; 'mobility'; 'territory'; 'sustainable'; 'active modes', etc. }\end{array}$ \\
\hline & $\begin{array}{l}\text { [G] } \\
\text { Elimination of } \\
\text { precise space- } \\
\text { time references }\end{array}$ & $\begin{array}{l}\text { This element has to do with a spatio- } \\
\text { temporal fuzziness, when propositions are not } \\
\text { associated with a precise location or time horizon }\end{array}$ & $\begin{array}{l}\text { Cardinal points ('nord' ; 'sud'; 'est'; ' 'ouest') ; street names (' rue ...' ; } \\
\text { 'boulevard...') ; the parts of the conurbation ('centre-ville' ; 'centre' ; } \\
\text { 'agglomération' ; 'axes'...) ; time units ('jour' ; 'mois' ; 'année' ; 'heure') }\end{array}$ \\
\hline & $\begin{array}{l}\text { [H] } \\
\text { Elimination of } \\
\text { references to } \\
\text { concrete devices }\end{array}$ & $\begin{array}{l}\text { The removal of words designating concrete } \\
\text { devices (and their replacement by abstract terms) }\end{array}$ & $\begin{array}{l}\text { Infrastructure ('stationnement' ; 'parc-relais'...) ; vehicles ('poids lourd' ; } \\
\text { 'automobile') ; modes ('transports en commun') ; concrete indicators ('accident' ; } \\
\text { 'vitesse' ...) }\end{array}$ \\
\hline
\end{tabular}




\subsection{Illustrative elements and their specificities}

Illustrations, by definition, should either (1) 'make clear' or (2) 'give an example' of the idea developed in a text (Collins Dictionary Online, 2020). Nevertheless, as we saw earlier, these types of representation are no less affected by vagueness than textual elements. Some of the illustrations in PDUs fail to 'make clear' or to 'give an example' and instead add vagueness to the discourse.

As with many planning documents, the illustrative elements of our corpus can be divided into maps, pictures, diagrams and various graphs and tables. In such a corpus, illustrative elements provide less data (in quantity) than text does. For the 36 PDUs considered, 3,852 visuals were identified (with an average of 0.73 per page) thereby allowing a 'classical' reading (i.e. without the help of software). During the visual content analysis phase, the criteria for selecting a 'vague visual' were simple and followed the definition above: (1) Is the illustration clear in its content? (2) Does it give an example of what is written beside it? Where illustrations failed to provide clarity (even partly) or examples, we identified them as imparting substantial vagueness.

It is worth noting here that a clear difference was made between 'schematized' visuals and 'vague' visuals that are very different in nature. Schematization is common in planning documents and relies on the principle of simplifying reality to focus on a limited series of aspects considered as most important and that are put forward in the visual. Our corpus of 36 documents contained 1,177 maps including 78 schematized maps (6.6\%) (see Figure 1). Schematized maps differ from vague maps as they convey a simplified vision presented as such without seeking to blur information or take advantage of semantic ambiguities.
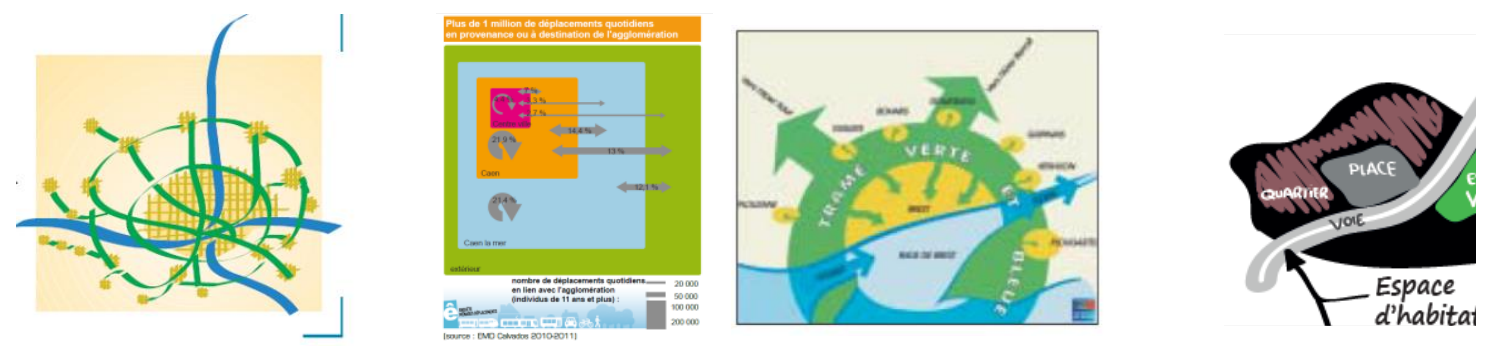

Figure 1: Schematized maps provide simplification but not fuzziness (Nantes 2000; Caen 2013; Brest 2002; Besançon 2015) 


\section{RESULTS}

\subsection{Vagueness in text: a diffuse and essential ingredient of planning prose}

Queries performed by textometry and validated by qualitative readings on different types of substantially vague elements yield the following results (see Table 3). In all 25,670 occurrences were found in the corpus, with an average of 16 fuzzy terms every 1000 words. This might seem rather few at first sight but it corresponds to an average of five substantially vague words or phrases on each page of the whole corpus. This overall result underlines the quantitative importance of vagueness as a diffuse and inconspicuous language artefact.

\begin{tabular}{|c|c|}
\hline Substantially vague textual elements & $\begin{array}{l}\text { Number of occurrences (and } \\
\text { relative number per 1,000 words) }\end{array}$ \\
\hline [A] Concessionary wording & 219 occ. $(0 \%)$ \\
\hline [B] Verb nominalizations & 8,038 occ. $(5 \%)$ \\
\hline $\begin{array}{l}\text { [C] 'Comparative adjectives without } \\
\text { comparison' }\end{array}$ & 344 occ. $(0 \%$ o) \\
\hline [D] 'Pointless conjunctions' & 6,814 occ. $(4 \%)$ \\
\hline [E] 'Positivity effects' & 60 occ. $(0 \%$ o) \\
\hline [F] Vague concepts & 10,195 occ. $(6 \%$ o) \\
\hline Sub-total 'vague elements' & 25,670 occ. $(16 \%)$ \\
\hline $\begin{array}{l}\text { [G] Elimination of space-time } \\
\text { references }\end{array}$ & $\begin{array}{l}1^{\text {st }} \text { gen. PDUs: } 4,052 \text { occ. }(7 \% \circ) \\
2^{\text {nd }} \text { gen. PDUs: } 6,028 \text { occ. }(5 \%)\end{array}$ \\
\hline $\begin{array}{l}\text { [H] Elimination of references to } \\
\text { concrete devices }\end{array}$ & $\begin{array}{l}1^{\text {st }} \text { gen. PDUs: } 11,754 \text { occ. }(21 \%) \\
2^{\text {nd }} \text { gen. PDUs } 21,951 \text { occ. }(19 \% \text { o) }\end{array}$ \\
\hline Sub-total 'elimination of precision' & $\Delta=-4 \%$ \\
\hline
\end{tabular}

Table 3: Quantification of the different features of textual fuzziness

Not every kind of vagueness is quantitatively of the same importance, following a general rule. The least directly detectable types (nominalizations, conjunctions) are the most frequent. The rhetorical-type discourse elements (such as positivity and concessionary wording) that are more easily detectable by readers are also rarer. That said, they are more often found in titles (catchphrases) and seem potentially more important in the discourse than their quantified record suggests.

An elimination of rather precise elements can also be identified between the two generations of documents. Although the absolute number of precise terms increases, second-generation 
documents (of the years 2010s) are twice as long $(1,126,000$ words versus 547,000 for the same number of documents). In relative terms, rather precise terminology shrank from $28.88 \%$ to $24.83 \%$ in ten years.

In order to analyse more clearly the change in textual vagueness over the period 2000-2015, the 36 PDUs were plotted in a two-dimensional space (see Figure 2). As categories of textual vagueness can either be expressed positively (categories A to $F$ ) or negatively ( $G$ and $H$ ) documents are represented on a plane where $Y$ is the number of all the occurrences of substantially vague terms per 1000 words and $X$ expresses the number of occurrences of rather precise terms per 1000 words.

INSERT FIGURE 2 (Caption: Documents discourse trajectories considering fuzziness and precision)

Figure 2 shows a general transition that implies vagueness in PDUs between their first and revised versions. Most cities doubled their relative level of vagueness over the decade. At the same time, almost every city also reduced its relative level of precision. Of 18 cities, 15 experienced an increase in fuzziness combined with a decrease in precision over this period. Two cities (Dijon and Toulouse) saw an increase in textual fuzziness combined with a much smaller increase in precision. When combining these two criteria, their trajectory is nevertheless characterized by an increase in the vagueness/precision ratio. In this corpus, Aix-en-Provence is a noteworthy exception. This city was the most textually vague PDU in the first generation (in the 2000s). It followed the opposite trajectory to all the others by proposing a revised document in 2015 that was more precise, and even the most precise document of the second generation of PDUs. Aix-en-Provence is one of the few cities in the corpus not to have had any infrastructure project in the decade 2000. On the contrary, it planned a BRT for 2020 in its second generation PDU (2015) where this proposal was prominent in the document. This explains its 'reverse' trajectory of textual fuzziness in relation to all the other cities in the corpus. 


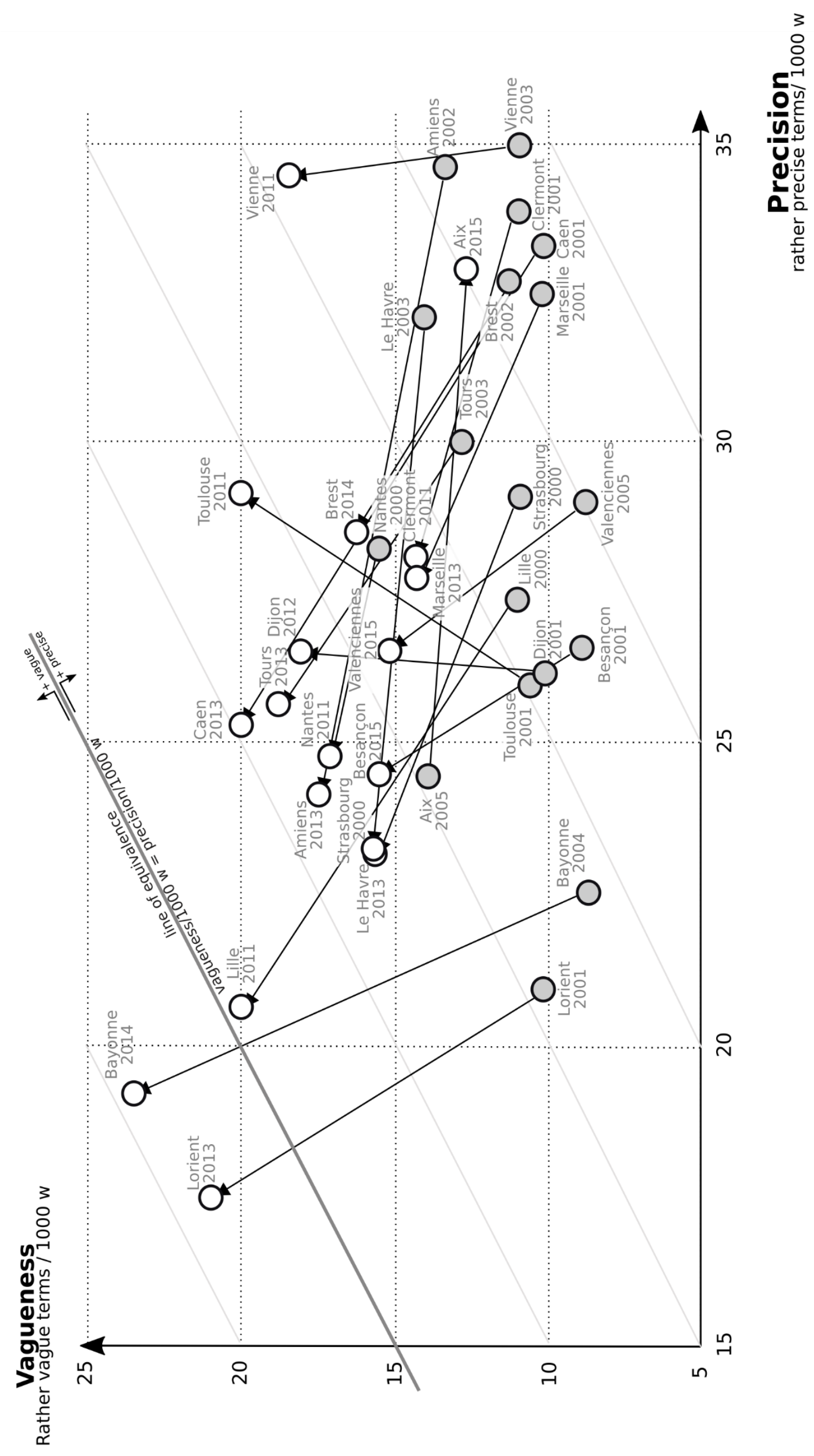


Textual vagueness is a diffuse and important element for planning discourse. When monitored over time, vagueness turns out to be a growing phenomenon concerning 17 out of 18 French cities. This result must be combined with an analysis of visual elements in order to better describe the general change in discourse.

\subsection{Visual fuzziness: rather rare but associated with core illustrations}

In the whole corpus, visual vagueness concerns 38 different illustrations. In quantitative terms, its presence is more discreet than in texts as only $1 \%$ of the visuals are concerned, or as only $56 \%$ of documents are concerned by at least one vague visual. Nevertheless, they concern highly strategic sections of the documents as they can be found almost exclusively in chapters on 'strategy', 'objectives' and 'projects'.

Not all types of illustrations are equally affected by fuzziness. Maps are more concerned $(2.88 \%$ of them can be considered 'vague') than graphs and tables (0.39\%). Diagrams are not concerned as they correspond to the 'schematized visuals' we excluded from the analysis earlier. The case of pictures (photographs, aerial views, photomontages) is less clear-cut. A small minority of them provide precise information about the planned developments in the form of photomontages or about recent achievements (98 pictures or $6.81 \%$ ). The rest of the pictures are of the city, most often with a heritage slant and scenes of urban travel usually involving walking and cycling. In order not to overestimate vagueness in our corpus we decided to considered the majority of pictures as 'not vague' in that they represent an implicit desirable future for planning actors even if no tangible information can be extracted from them. ${ }^{7}$

It is noteworthy that of 38 fuzzy visuals found in the corpus, only four different (and repeated) forms are observed and will be developed here.

'Filling-in maps with fuzzy objects'

\footnotetext{
7 That said, further research on the use of pictures in planning would be useful since the population, practices and places represented seem particularly selective.
} 
A first way to inject fuzziness into the visual discourse relies on drawing maps with unclear objects. Figure 3 (see below) is a typical example. Most of the elements on the map are commonplace and precise: linear elements represent a series of current and future public transport lines; yellow and red areas mark public transport coverage zones. However, green areas represent a particularly vague object, labelled in the key as 'developments for active modes'. ${ }^{8}$ Their surface area covers the entire built-up area of all the municipalities included in the PDU. No concrete element is to be found anywhere in the document to explain the actual content of these 'developments' whether technical specifications, their geography, time horizons or budgetary items.

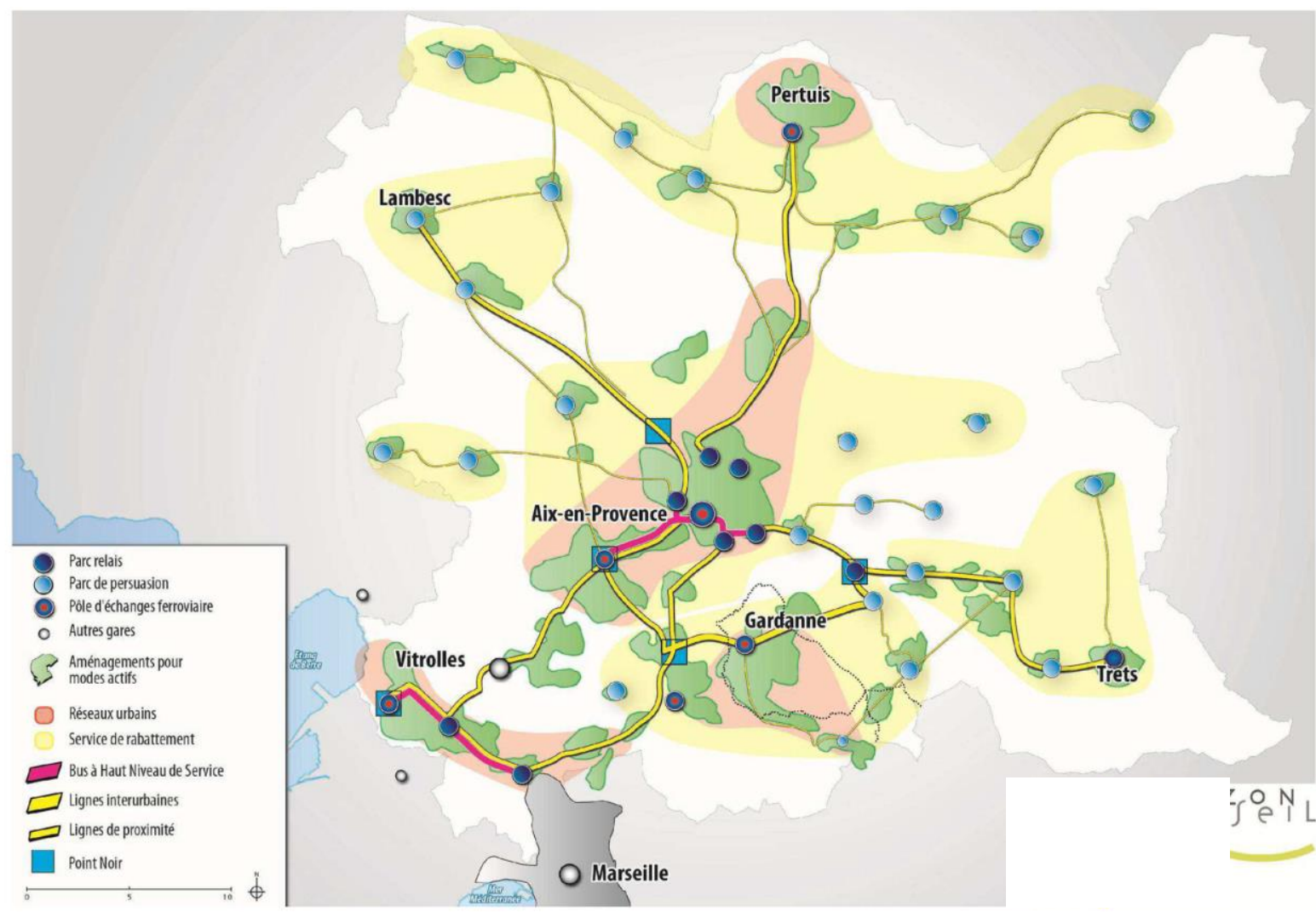

Figure 3: An example of filling-up maps with vague objects (Aix-en-Provence, 2015, p.74)

Figure 3 is not an isolated phenomenon as 23 maps are concerned by vague objects on maps within the corpus. Figure 4 shows another example in Bayonne (2014) where the light blue areas 
correspond to another particularly unclear content: 'supporting local alternatives to single occupancy car-use' ${ }^{9}$ Again nothing is specified in the rest of the document.
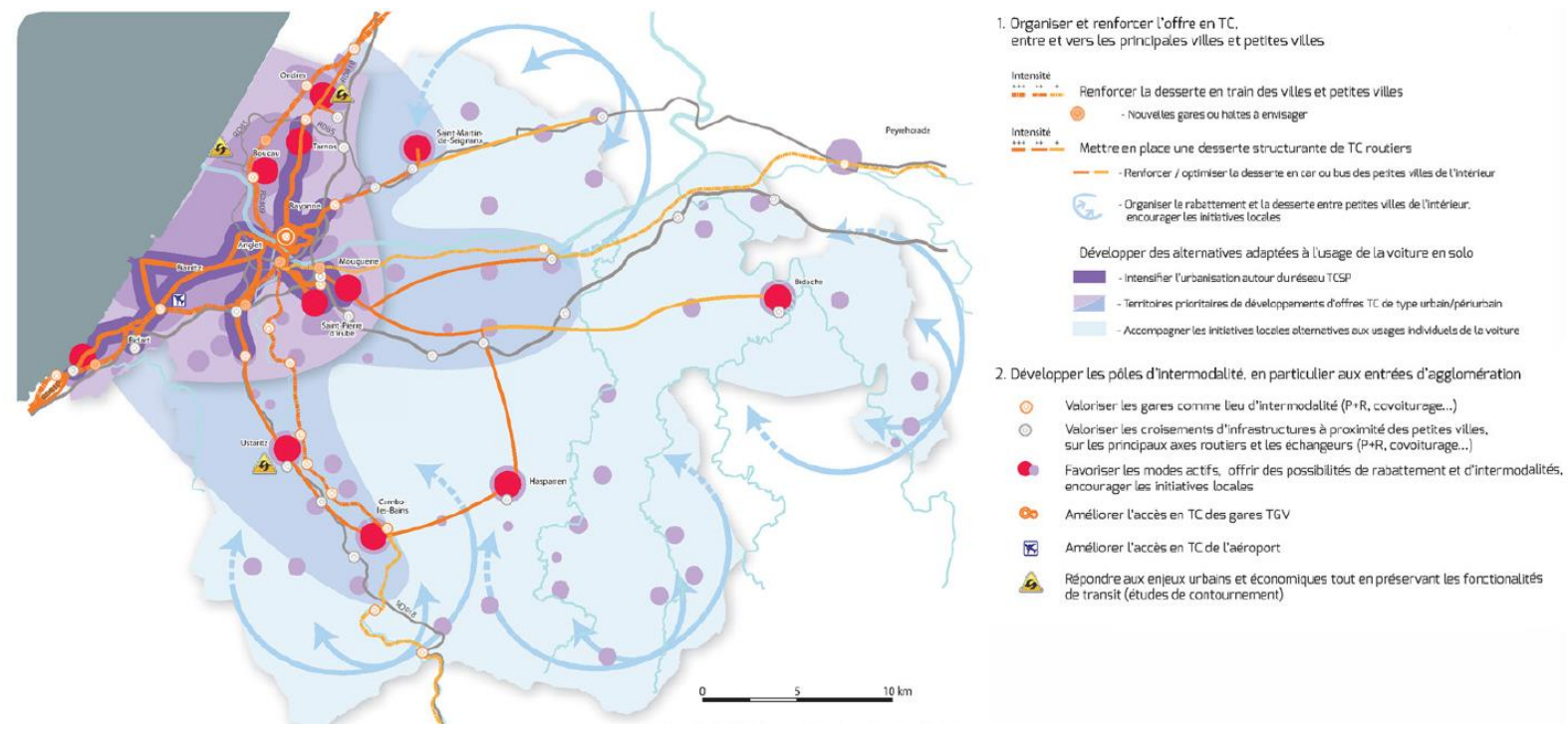

Figure 4: Vague cartographic objects make it possible to come up with a proposal for any municipality (Bayonne 2014, p. 7)

The green areas in Figure 3 and light-blue areas in Figure 4 seem to have a common target: filling-in the maps in a vague way so as not to leave any part of the territory without a proposal. In France, as in many other countries, urban transport planning is often criticised for focusing its actions on the central municipalities to the detriment of the outskirts, whether by choice of dominant municipalities or by lack of interest of peripheral ones (Offner, 2006). These maps most likely seek to alleviate that feeling of 'centrophilic policies'.

Keys and footnotes that make their respective objects meaningless

Another form of vagueness is produced by associating very precisely located and denominated objects with a key category whose wording tends to void it of its content. Figure 5 shows a cycle path network with structural, local and leisure oriented sections, together with sections 'to be validated' without any clarification in the associated text. Several interpretations may be made: the route of the cycle path, its funding or the decision to actually build it could be 'validated' later (by a process and by people yet to be defined). Figure 6 adopts similar tactics because the modal 'could' (be brought into

\footnotetext{
9 'Accompagner les initiatives locales alternatives aux usages individuels de la voiture'
} 
service) and the word 'possibility' (of road refurbishment) calls into question the construction of these developments, even though they have been very precisely mapped and described. In other documents, the content of maps is sometimes voided of legal significance by a footnote specifying that the construction or the precise locations of infrastructures and facilities depicted are not legally binding ${ }^{10}$ (e.g. Montpellier 2012, pp. 156-161).

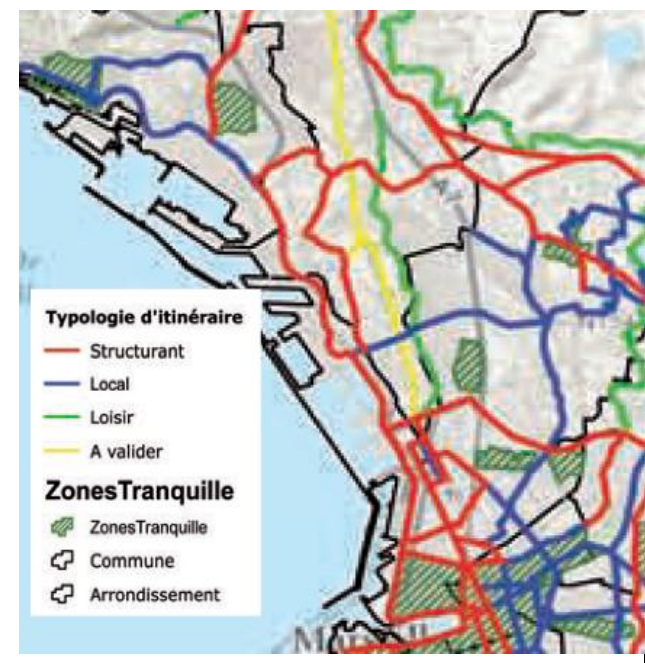

Figure 5: 'To be validated' (close-up)

(Marseille 2013, p.47)

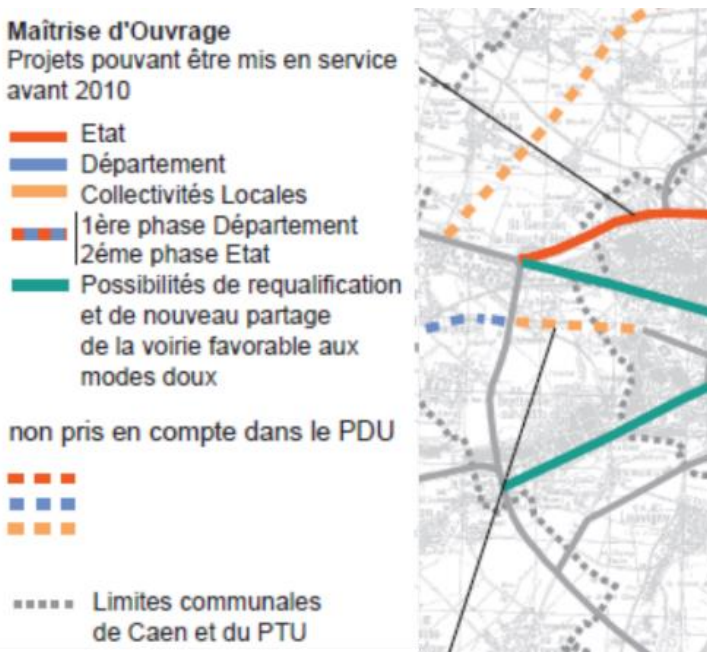

Figure 6: 'Project that could be put into service before 2010' (Caen 2001, p.76)

\section{Assigning vague time horizons or objectives}

Although they are not the most important vector of vagueness, graphics can also display unclear content. Figure 7 (below) is a typical example: as in all other PDUs modal share objectives are defined here, but with a vague time horizon: 'tomorrow' ('demain'). Whereas 'today' can be assumed to be the year the document was approved, it seems difficult to define 'tomorrow' precisely.

\footnotetext{
${ }^{10}$ The excerpt reads: 'This map is a reference scheme that is not legally binding on the various relevant authorities in terms of programming for the duration of the plan.'
} 


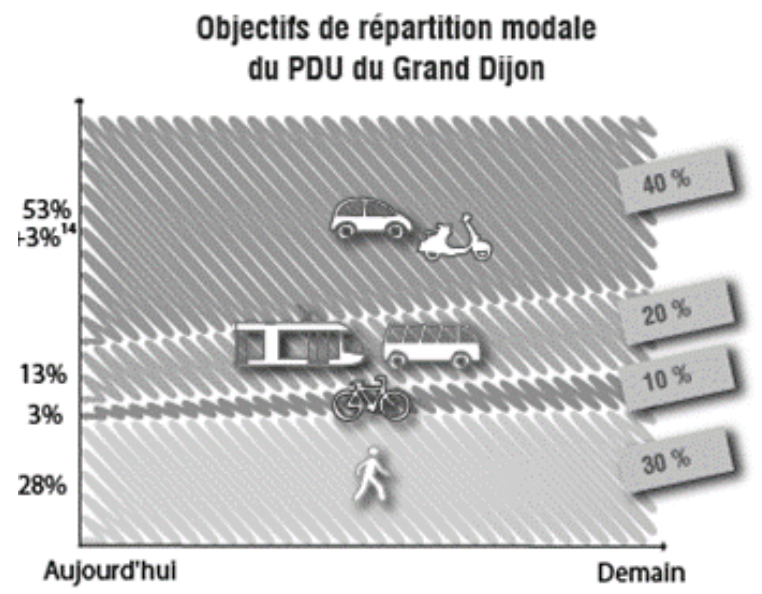

Figure 7: Precise modal objectives for 'tomorrow' (Dijon 2012, p. 67)

Vague indicators that drive strategy

Synthetic indicators are also subject to vagueness when their methodology is not explicit or no explanation of their content is given. Scale-indicators of Figure 8 are reproduced sixteen times to synthetize the probable impacts of sixteen recommended actions. No methods or clarifications are given as to how these indicators are measured. Some are understandable but their methodology seems particularly challenging and difficult to be put in place in the framework of a PDU. The impact of a particular measure on 'mobility practices' or 'environmental impact' would require simulation methods with very complex protocols not followed here. Other indicators are loosely defined. For example, who is considered to have an 'interest in the initiative' ('intérêt pour la demarche'): The population? The elected officials of the different municipalities? The targeted population of singleoccupancy drivers? These fuzzy indicators are found in three different documents and seem to be used as authoritative arguments to justify actions.

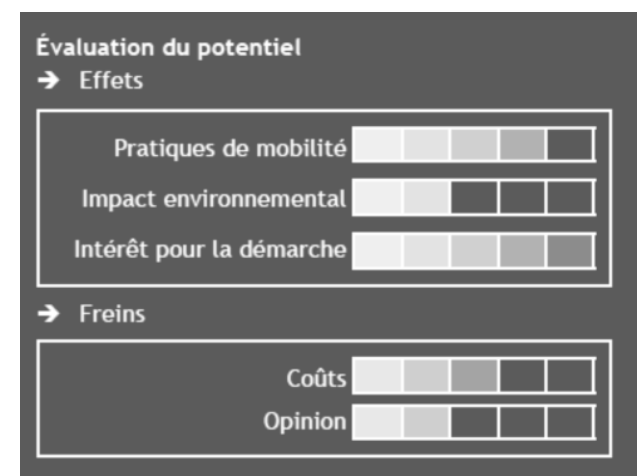

Figure 8: Vague indicators (Bayonne, 2014, p. 13) 
Overall, in our corpus, vagueness is less visual than textual. On average, visual vagueness only occurs about every 50 pages. That said, as just seen, this type of vagueness attacks key elements in the argumentative and logical construction of documents: strategic maps, justifying indicators or time horizons for modal share objectives. Visual vagueness, although sporadic or marginal in terms of surface area occupied, seems much more insidious in that just a few graphic operations may divert part of the whole process and its relevance.

\section{WHAT RATIONALES LIE BEHIND THE USE OF VAGUENESS IN PLANNING?}

The presence of this unclear register raises questions about the reasons that could push planning actors $^{11}$ to sometimes use it rather than respond to the legal expectations about developing explicit strategies and actions. The increase in vagueness identified in our corpus, whether textual or visual, between the years 2000 and 2010, raises questions. In the constrained volume of an article we will focus the discussion part on a series of five explanatory paths that make the most sense in the context of French PDUs bearing in mind that most of these are applicable to other countries.

(1) Forming temporary coalitions is a credible assumption. In the French system of governance, the central municipality almost systematically controls the inter-municipal body as each municipality is represented proportionally to its population. Nevertheless, central municipalities often need larger majorities to pass their plans. As in many other countries, the elected representatives of most outlying municipalities are reluctant to introduce measures restricting car use. Proposing vague actions as in Bayonne (Figure 4) is an example of such a hidden strategy to forge broad majorities despite their antagonistic positions on 'sustainable transport' issues. This type of configuration illustrates the idea of vague signals that only certain actors can decipher (Kaza and Hopkins, 2009). Indeed, in Bayonne some peripheral municipalities which are reluctant to act against car-use may be given to understand

\footnotetext{
${ }_{11}$ Planners are probably not the prime suspects for this vagueness. Elected officials, communication consultants and legal departments involved in the process are likely to have a healthier appetite for vagueness.
} 
by the vague action of 'supporting local alternatives to single occupancy car-use' that nothing will be imposed on them by the inter-municipal body.

(2) Vagueness might also be purely tactical, when planning actors want to keep information to themselves or to reveal it only in private. An important event occurred in Grenoble in 2007, between the two waves of PDUs in our corpus. The prefect (governor) rejected the pre-approved PDU following appeals from pedestrian and cyclist associations about sharing the roadway in a planned tunnel, which was considered unsuitable for walking or cycling. These appeals were based on very precise elements of the PDU submitted for approval: road plans and photomontages. Giving precise details of a plan can sometimes mean arming opponents or competing groups with arguments and information. These elements can then be used in legal proceedings, sometimes in litigation. The case of rejection of Grenoble's PDU was widely disseminated in professional planning circles and set a new precedent. Considering this overall context, the increased vagueness seen in the second generation PDUs (2010s) comes as no surprise. Vague formulations are much more difficult to contest in the courts and therefore such formulations seem to be of great value - sporadically - to local authorities. Figure 5 is a good example of this issue. A cycle path, almost everything of which remains 'to be validated' (precise layout, design, number of car parking spaces removed, time frame), could be put in place. This does not represent sufficient grounds for appeal by associations or other groups that might object to it.

More generally, unclear discourses enable actors to manage the many uncertainties of planning, whether related to budgets for the coming decade (especially those from co-funders such as central government or regional councils), potential legal appeals or other technical vagaries. This rationale supplements previous research on the issue of publicising (or not) a plan (Kaza and Hopkins, 2009). Between publicising a plan or not, when making a plan is mandatory, vagueness is an in-between for public authorities that allows them to say little on certain strategic subjects.

(3) The increased vagueness in our corpus might also be the result of the mandatory environmental evaluation introduced between the first and second generations of PDUs. It seems prudent to be vague about objectives knowing that the impacts of previous decisions will be evaluated. 
Admitting a past error of appreciation and false forecasts is still considered taboo in the political discourse of elected representatives in several countries including France (Kaza, 2019). In Dijon, in the coming years if objectives are not attained, some may argue that 'tomorrow' did not meant '2020' but later (see Figure 7). As Russell (1923) stated, vagueness maximises the likelihood of being true. In pragmatic political terms, the presence of unclear elements makes it easier to build fallacious but coherent justifying arguments a few years down the line.

(4) Another explanatory path is to be found in the particular time-frame of French cities. Most inaugurated a tramway or BRT in the 2000s. The revised version, a few years later, contains more vagueness because considerable financial means have already been invested and no or few new projects can be envisaged in the short term. Vagueness helps to create the impression of there being greater willingness or capacity to act than there really is. As mentioned above, the legal framework compels cities to develop a strategy for reducing single-occupancy car-use in the city. When willingness to act is rather weak for a local authority on a specific topic, but when the related planning exercise is imposed from the outside, discursive vagueness becomes a solution for hedging against firm commitments. These formulations make it possible to be less precise (in terms of timeframe, space and concrete objects to be implemented) and to be vaguer about the objectives and actions, while securing external co-funding for possible extensions and refurbishments of the public transport network. The very sharp increase in the occurrence of conceptual terms in the years 2010 illustrates this appetite to avoid precise commitments on certain topics imposed from the outside.

(5) Finally vagueness might also be considered a longer-term strategy. Getting reluctant municipalities and sectors of the population to accept unclear solutions in the first instance would make it possible, when the document is revised, to increase the pressure to clarify the actions to be implemented, in a two-step approach mobilising vagueness. The cycle path 'to be validated' (see Figure 5) can be understood as a way of smoothly orienting collective action and future partners (in this case a municipality) towards projects designed for the medium term. Vagueness here has a final function 
for a local authority: to quickly register a distant project in documents in order to give it consistency; and to enhance the irreversibility of its future implementation.

\section{CONCLUSION}

Our analysis has detected numerous elements of vague discourse in a corpus of planning documents. These elements are used only sporadically, but most often concern extremely important parts of these documents (i.e. the strategy deployed, the objectives or even the selected technical solutions). Furthermore, these results show that the discursive vagueness in planning affects far more than just concepts; it concerns a much broader set of elements, both textual and visual, and is spread throughout the discourse.

Although our results are not entirely generalisable to all types of planning, ${ }^{12}$ it is highly unlikely that such vagueness is exclusive to local transport plans in France. On the contrary, the present results indicate that vagueness is an important discursive tool, the importance of which lies between a minimum of vagueness inherent in all representation, and a maximum that would discredit the document. This level of vagueness can be used gradually depending on the situation, and is used at its maximum in adverse circumstances when the city does not want to express firm commitments and/or when it thinks it is more strategic to reveal its 'true' plan later (Kaza and Hopkins, 2009). There is therefore an alternative to the possibilities of whether or not to publicise a plan. This alternative consists in the vague wording of part of a plan, so as not to reveal anything that would be too great a commitment or reveal too many details to other actors. Although the rationales for its use are multiple and still require direct empirical validation in different contexts, it seems clear that vagueness is a sufficiently satisfactory solution for actors when the tensions with other actors and uncertainty about

\footnotetext{
12 These results may not be entirely generalisable in the sense that other types of plans such as land-use plans require more concern for detail, at least in their regulatory sections (plans of zones and rules). Precision and explicit formulation are there vital as no room must be left for misinterpretation. When it comes to what can or cannot be done on a plot of land, vagueness seems useless or even dangerous for the local authority. That said, it is likely that vagueness is more specific to strategic planning documents such as PDUs, and in the 'strategy' and 'objective' sections of land-use plans (i.e. 'PLUs' in France).
} 
the future becomes too great. Vagueness thus succeeds in instituting a paradox with respect to certain topics: turning 'plans' into documents that no longer explain what is 'planned'. 


\section{REFERENCES}

Bugg L and Gurran N (2011) Urban planning process and discourses in the refusal of Islamic Schools in Sydney, Australia. Australian Planner 48(4): 281-291. DOI: 10.1080/07293682.2011.593531.

Buhler T and Lethier V (2019) Analysing urban policy discourses using textometry: An application to French urban transport plans (2000-2015). Urban Studies: 004209801987382. DOI: $10.1177 / 0042098019873824$.

Collins Dictionary Online (2020) Collins Dictionary Online. Available at: https://www.collinsdictionary.com/dictionary/english.

De Roo G and Porter G (eds) (2007) Fuziy Planning: The Role of Actors in a Furay Governance Environment. Aldershot, England ; Burlington, VT: Ashgate.

Fairclough N (2013) Critical Discourse Analysis: The Critical Study of Language. 2. ed., [Nachdr.]. London: Routledge.

Hansson L (2020) Visual representation in urban transport planning: Where have all the cars gone? Transportation Research Part A: Policy and Practice 133: 1-11. DOI: 10.1016/j.tra.2019.11.027.

Hoch C (2007) Making Plans: Representation and Intention. Planning Theory 6(1): 16-35. DOI: $10.1177 / 1473095207075148$.

Hopkins LD (2001) Urban Development: The Logic of Making Plans. Washington, DC: Island Press.

Hopkins LD (2007) Using Plans and Plan Making Processes: Deliberation and Representations of Plans. In: Engaging the Future: Forecasts, Scenarios, Plans, and Projects. Cambridge, MA: Lincoln Institute of Land Policy.

Hopkins LD and Knaap G-J (2018) Autonomous planning: Using plans as signals. Planning Theory 17(2): 274-295. DOI: 10.1177/1473095216669868.

Hopkins LD and Knaap G-J (2019) The "Illinois school" of thinking about plans. Journal of Urban Management 8(1): 5-11. DOI: 10.1016/j.jum.2019.02.001.

Jacobs K (2006) Discourse Analysis and its Utility for Urban Policy Research. Urban Policy and Research 24(1): 39-52. DOI: 10.1080/08111140600590817.

Jegen M and Mérand F (2014) Constructive Ambiguity: Comparing the EU's Energy and Defence Policies. West European Politics 37(1): 182-203. DOI: 10.1080/01402382.2013.818325.

Kaza N (2019) Vain foresight: Against the idea of implementation in planning. Planning Theory 18(4): 410-428. DOI: 10.1177/1473095218815201.

Kaza N and Hopkins L (2009) In What Circumstances Should Plans Be Public? Journal of Planning Education and Research 28(4): 491-502. DOI: 10.1177/0739456X08330978.

Kaza N and Hopkins LD (2012) Intentional actions, plans, and information systems. International Journal of Geographical Information Science 26(3): 557-576. DOI: 10.1080/13658816.2011.603337. 
Keefe R (2000) Theories of Vagueness. Cambridge studies in philosophy. Cambridge, UK ; New York: Cambridge University Press.

Krieg-Planque A (2012) Analyser les discours institutionels. S.l.: Armand Colin.

Krieg-Planque A and Oger C (2010) Discours institutionnels.Perspectives pour les sciences de la communication. Mots (94): 91-96. DOI: 10.4000/mots.19870.

Lexico Oxford Dictionnary (2020) Resource. Oxford University Press. Available at: https://www.lexico.com/definition/resource (accessed 14 September 2020).

Maccallum D and Hopkins D (2011) The Changing Discourse of City Plans: Rationalities of Planning in Perth, 1955-2010. Planning Theory \& Practice 12(4): 485-510. DOI: 10.1080/14649357.2011.626313.

Matthews P and Satsangi M (2007) Planners, developers and power: A critical discourse analysis of the redevelopment of Leith Docks, Scotland. Planning Practice and Research 22(4): 495-511. DOI: $10.1080 / 02697450701770043$.

Offner J-M (2006) Les plans de déplacements urbains. Paris: La Documentation française.

Pineira-Tresmontant C (1988) Rigidités discursives et flou sémantique. Mots 17(1): 145-169. DOI: $10.3406 /$ mots.1988.1402.

Porter G and De Roo G de (2007) The End has no Merit. In: De Roo G and Porter G (eds) Fuz:y Planning: The Role of Actors in a Fuzzy Governance Environment. Ashgate, pp. 1-20.

Portugali J and Alfasi N (2008) An Approach to Planning Discourse Analysis. Urban Studies 45(2): 251-272. DOI: 10.1177/0042098007085962.

Russell B (1923) Vagueness. Australasian Journal of Psychology and Philosophy 1(2): 84-92. DOI: 10.1080/00048402308540623.

Sabatier PA (2010) Advocacy coalition framework (ACF). In: Dictionnaire des politiques publiques. Références. Paris: Presses de Sciences Po, pp. 49-57. Available at: https://www.cairn.info/dictionnaire-des-politiques-publiques--9782724611755-p-49.htm.

Saussure F de (2005) Cours de linguistique générale. Éd. critique, [Nachdr. der Ausg. 1916]. Grande bibliothèque Payot. Paris: Payot.

Shapiro S (2008) Vagueness in Context. Oxford: New York: Clarendon Press ; Oxford University Press.

Sorensen R (2018) Vagueness. In: The Stanford Encyclopedia of Philosophy (Summer 2018 Edition). Available at: https://plato.stanford.edu/archives/sum2018/entries/vagueness/.

Thom F (1987) La Langue de Bois. Commentaire Julliard. Paris: Julliard. 